\title{
Pondering farmworker justice: The visible and invisible borders of social change
}

COMMENTARY ON RACE AND ETHNICITY IN FOOD SYSTEMS WORK

\author{
Anna Erwin* \\ Virginia Tech
}

Submitted June 15, 2015 / Published online February 1, 2016

Citation: Erwin, A. (2016). Pondering farmworker justice: The visible and invisible borders

of social change. Journal of Agriculture, Food Systems, and Community Development, 6(2), 29-33.

http://dx.doi.org/10.5304/jafscd.2016.062.007

Copyright (C) 2016 by New Leaf Associates, Inc.

\begin{abstract}
Farmworkers play an integral part in both industrial and alternative agriculture, and in recent years the alternative agriculture and farmworker justice movements have been collaborating in more fruitful ways. These collaborations are applauded and are definite steps in the right direction; however, unlike many members of the alternate agriculture community, many farmworkers are discriminated against for their race, class, and citizenship status. These realities endure in that $25 \%$ to $50 \%$ of farmworkers are estimated to be undocumented individuals, new destinations for new farmworkers are often in states with tight immigration policies, and much of our immigration debate is based on a rhetoric of individual choice.

* Anna Erwin, 140 Otey Street NW; Blacksburg, Virginia 24060 USA; +1-910-620-6026; erwinae@vt.edu

Author note: Anna Erwin is a PhD student in the Planning, Governance, and Globalization program in the Virginia Tech School of Public and International Affairs.
\end{abstract}

As these types of partnerships become more common, power relations must be addressed and shifted if we wish to see more equal participation from both parties. This commentary outlines a framework for change at all levels of governance, and specifically expresses five ways in which the alternative agriculture movement can begin to shift power associated with race, class, and citizenship, and therefore create and maintain stronger partnerships with the farmworker community. These shifts will not happen overnight and will only occur if we work collaboratively to insist on a more transparent global capitalist system, advocate for immigration laws that are not based on fear, implement local food programs that include farmworker participation and input, and create new organizational policies that encourage individual voice and agency.

\section{Keywords}

immigration, alternative agriculture, farmworker justice, critical agrarian studies, social change 


\section{Introduction}

Farmworkers play a critical role in harvesting everything from our vegetables and fruits to our Christmas trees. They are not just temporary workers with legal documents, American citizens, or undocumented adults, but also youth who were raised as farmworkers and continue to work in the fields, some of whom are attending American schools and universities in the hope of contributing to the country they call home. These aspirations notwithstanding, these individuals still live and work in dangerous conditions and are often subject to discrimination on the basis of their race, class, and citizenship status. As a general proposition, it is fair to say that they are systematically rendered invisible to the broader society by both industrial and alternative agriculture (Gray, 2013; Holmes, 2013).

These realities are becoming more apparent to me, a white, middle-class locavore, as I begin my dissertation research on questions addressing justice for farmworkers, sustainable agriculture, and political voice and participation. Fortunately, many undocumented farmworkers are already demonstrating phenomenal courage by sharing their stories with the public through movements such as the DREAMers. Food justice and food sovereignty activists and scholars are also addressing these realities and highlighting linkages as well as gaps between the alternative agriculture movement and labor. Moreover, these actions are making headway in policy as the city of Los Angeles now incorporates standards for agricultural labor into its procurement policies. The goal of this brief commentary is to encourage both the alternative agriculture and the farmworker justice movements to deepen collaborations, to continue to investigate power and privilege, and ultimately to work together to imagine and implement collaborations and policies that foster social and ecological sustainability. In order to ensure that these partnerships flourish and to move toward broad-scale social change, differences arising from race, class, and citizenship privileges must not only be understood, but also be broken down at all levels of the collaborative movement.

In this piece, when referring "farmworkers" I am referring to the largely Latino population of temporary guest workers and undocumented, or unauthorized, farmworkers who are working in the United States without American citizenship. This does not discount the hard work on farms conducted by American citizens of all races nor the racial discrimination experienced by many farmworkers of color, but this particular piece focuses on the aforementioned populations. The statistics vary according to place and can be difficult to acquire, but it can be assumed that anywhere from $25 \%$ to $50 \%$ of farmworkers are undocumented immigrants (Passel \& Cohn, 2009). An earlier National Agricultural Workers Survey conducted by the U.S. Department of Labor found that $75 \%$ of farmworkers were born in Mexico (Carroll, Samardick, Bernard, Gabbard, \& Hernandez, 2005).

In many states, so-called undocumented individuals cannot obtain a driver's license, secure health coverage under the Affordable Care Act, or apply for other public services, such as the Supplemental Nutrition Assistance Program (food stamps). Difficult living and working conditions have been exacerbated in Arizona and Alabama in recent years by strict residency laws that limit laborers' mobility and freedom. In addition to these realities, farmworkers, regardless of status, traditionally make low wages, have higher levels of food insecurity than the general U.S. population, and work regularly in dangerous conditions (Arcury \& Marín, 2009; Gray, 2013). Although many workers mobilize against these conditions, their fear of deportation and loss of employment can limit their opportunities for organizing against unfair working conditions (Holmes, 2013).

Social change advocates and scholars strive to use governance processes and develop programs to change power relations between those with privilege and those without and thus increase the participation and encourage the exercise of political agency by the traditionally voiceless. However, because of the challenges that many guest workers and undocumented farmworkers face, it is difficult to create the sorts of shared social change processes that move society toward these goals. Development professionals and scholars argue that in order to shift existing power relations, and thus stimulate change, existing norms and social 
structures must be challenged at the level of the individual, the organization, and the state. Moreover, whatever the scale of activity necessary or envisioned, those experiencing injustices in the globalized economic system, such as farmworkers, must be able to point up those wrongs if they are ever to attain real change in their lives. Given the complexity of these necessities, I outline a framework that supports change at all levels of governance. More precisely, in what follows I identify different ways, expressed as five basic propositions, in which the alternative agriculture movement can begin to break down the power imbalances associated with race, class, and citizenship, and thereby create stronger partnerships with the farmworker community.

First, although farmworkers contribute to the economy and live within the borders of the U.S., guest workers and undocumented farmworkers cannot vote to help to determine those who will make the laws that structure their lives. As a consequence, alternative food activists and scholars need to look beyond agricultural policy, as important as that domain is, and press for labor and immigration reform. Advocates must also understand that today's often-dominant neoliberal rhetoric of individual choice and responsibility is largely inapplicable to undocumented farmworkers living in the U.S., who do not possess the rights or standing that rhetoric assumes.

Secondly, like many small farmers in the U.S., farmworkers are also suffering from larger shifts in the international economic system. For example, before passage of the North American Free Trade Agreement (NAFTA), many Mexican farmers supplied corn for consumers in their native country. However, after NAFTA's passage the low cost of subsidized U.S. corn undercut the price competitiveness of Mexican-grown corn. This shift in employment for Mexican farmers influenced the migration of Latinos into the U.S. over the last fifteen to twenty years. Not only has economic hardship led to systemic reasons for increased migration to the U.S. (contradicting the argument that migration is somehow a "choice" of those undertaking it), it also indicates that many Mexican workers living in the U.S. today were at one time farmers in their native land whose properties became uncompetitive and thus had to look elsewhere for work (Fernández-Kelly \& Massey, 2007).

It is therefore important to design advocacy strategies on the basis of an understanding of that shared concern. The costs of increased regulation aimed at ensuring fair labor conditions can create economic hardships for small farmers. However, if advocates can develop more opportunities for farmworkers and small farmers to collaborate and come to understand their shared interests vis-à-vis changing international trade patterns and conditions, they will be able to discern opportunities to challenge the ongoing deregulation of the global corporate food industry. This imperative includes, but is not limited to, paying close attention to international trade agreements, such as the Transnational Pacific Agreement, as the results of treaties can be immense for small farmers and farmworkers alike.

Third, while the majority of farmworkers living in the U.S. still reside in traditional locations, such as California and Texas, the last 20 years have seen dramatic increases in Latino populations in other rural parts of the U.S., particularly the South (Passel \& Cohn, 2009). This is due partly to the fact that southern states have historically had lax labor-protection laws, and partially to global shifts that have made the South a particularly attractive place to do business (Ansley \& Shefner, 2009). Those working in the alternative agriculture movement must realize that issues of farmworker justice extend well beyond their traditional locations, and as Alabama has illustrated in recent years, that fact may result in significant social tensions. The many white citizens who dominate the alternative agricultural system movement have the power to move freely without fear of racial discrimination or deportation, and they should use that opportunity to advocate for policies at the local level that encourage openness to undocumented individuals in public schools, universities, hospitals, and social service agencies.

Fourth, locavores need to cultivate local food campaigns and projects that demonstrate the possibility of an open, dynamic, globalized understanding of the local. In addition to being laborers, farmworkers are also consumers, and thus can have 
valuable impact on a local food project's trajectory through providing input on the kinds of local foods available. In addition, food movement members must work to understand different cultures and their understandings of what constitutes healthy food and incorporate those into their short- and long-term plans for more economically, socially, and ecologically sustainable food systems. Local food consumers and advocates need to be mindful that labor injustices have been documented at all levels of agricultural production, from industrial agriculture to organic and small "local" farms (Gray, 2013; Guthman, 2004). The injustices workers experience are not limited to industrial agriculture alone. This fact makes it imperative that those seeking farmworker justice utilize every effort to change the culture associated with the alternative agriculture movement to heighten awareness of this reality. Scholars and activists recommend talking with small farmers about labor conditions on their farms and launching sustained efforts to seek improved health and safety working conditions on both small and large farms. It is also worth recalling that advocacy by many farmworkers is limited by fear of deportation and by their relative social isolation. Therefore, those seeking more just food systems cannot reasonably expect these individuals to go to food policy council meetings or attend farmers markets regularly. Instead, local food movement members must make efforts to go to where farmworkers live, work, eat, and worship if they wish to help them express a social and political voice (Gray, 2013).

Fifth, to understand farmworker issues those engaged must work closely with members of these groups. In conjunction with creating experiences to understand better the conditions of workers' lives, it is also important that advocates seek to create new spaces in which farmworkers can address injustices and imagine new possibilities with alternative agriculture professionals. Many development scholars advocate for what they call embodied cognition (Pettit, 2012), which includes incorporating theater, popular education, community gardens, and other engagement strategies to galvanize increased farmworker participation and voice in decision-making and processes that can affect them.
As the alternative agriculture and farmworker labor movements continue to explore collaboration in the name of social and ecological justice, their members must realize that understanding and changing the power relations that I have here outlined will not happen overnight. It can only occur if those engaged collectively advocate for a more transparent global economic system, for immigration laws that do not discriminate against specific groups on the basis of fear or other irrelevant criteria, for local policies (and citizenries) that are open to new immigrants, and for innovative organizational policies and programs that encourage the expression of individual voice and agency.

\section{References}

Ansley, F., \& Shefner, J. (2009). Global connections and local receptions: New Latino immigration to the southeastern United States. Knoxville: University of Tennessee Press.

Arcury, T. A., \& Marín, A. J. (2009). Latino/Hispanic farmworkers and farm work in the eastern United States: The context for health, safety, and justice. In S. A. Quandt \& T. A. Arcury (Eds.), Latino farmworkers in the eastern United States: Healthy, safety and justice (pp. 15-36). New York: Springer. http://dx.doi.org/10.1007/978-0-387-88347-2 2

Carroll, D., Samardick, R. M., Bernard, S., Gabbard, S., \& Hernandez, T. (2005). Findings from the National Agricultural Workers Survey (NAWS) 2001-2002 (Research Report No. 9). Washington, D.C.: U.S. Department of Labor. Retrieved from http://www.doleta.gov/agworker/report9/naws rpt9.pdf

Fernández-Kelly, P., \& Massey, D. S. (2007). Borders for whom? The role of NAFTA in Mexico-U.S. migration. The Annals of the American Academy of Political and Social Science, 610(1), 98-118. http://dx.doi.org/10.1177/0002716206297449

Gray, M. (2013). Labor and the locavore: The making of a comprehensive food ethic. Oakland: University of California Press.

Guthman, J. (2004). Agrarian dreams: The paradox of organic farming in California. Oakland: University of California Press.

Holmes, S. (2013). Fresh fruit, broken bodies: Migrant farmworkers in the United States. Oakland: University of California Press. 
Passel, J. S., \& Cohn D. (2009). A portrait of unauthorized immigrants in the United States. Washington, D.C.:

Pew Research Center. Retrieved from

http://www.pewhispanic.org/2009/04/14/a-

portrait-of-unauthorized-immigrants-in-the-unitedstates/
Pettit, J. (2012). Empowerment and participation: Bridging the gap between understanding and practice. Sussex, UK: Institute of Development Studies, University of Sussex. Retrieved from http://www.un.org/esa/socdev/egms/docs/2012/ JethroPettit.pdf 